\title{
Functional changes are associated with tracheal structural abnormalities in patients with acromegaly
}

\author{
Gustavo Bittencourt Camilo ${ }^{1,2}$, Fernando Silva Guimarães ${ }^{3,4}$, Roberto Mogami ${ }^{1,2}$, \\ Alvaro Camilo Dias Faria 5 , Pedro Lopes Melo ${ }^{1,5,6}$, Agnaldo José Lopes ${ }^{1,3}$
}

\begin{abstract}
${ }^{1}$ Post-graduate Program in Medical Sciences, State University of Rio de Janeiro, Rio de Janeiro, Brazil

2Department of Radiology, State University of Rio de Janeiro, Rio de Janeiro, Brazil ${ }^{3}$ Rehabilitation Sciences Post-graduate Program, Augusto Motta University Center, Rio de Janeiro, Brazil

${ }^{4}$ Department of Physiotherapy, Federal University of Rio de Janeiro, Rio de Janeiro, Brazil ${ }^{5}$ Biomedical Instrumentation Laboratory, Institute of Biology and Faculty of Engineering, State University of Rio de Janeiro, Rio de Janeiro, Brazil

${ }^{6}$ Post-graduate Program in Clinical and Experimental Physiopathology (FISCLINEX),

School of Medical Sciences, State University of Rio de Janeiro, Rio de Janeiro, Brazil
\end{abstract}

Submitted: 22 May 2015

Accepted: 30 June 2015

Arch Med Sci 2016; 12, 1: 78-88

DOI: 10.5114 /aoms.2016.57582

Copyright $\odot 2016$ Termedia \& Banach

\section{Abstract}

Introduction: Although impaired pulmonary function and respiratory sleep disorders are described as responsible for increased mortality in acromegalic patients, little is known about the tracheal abnormalities in this group of patients. Thus, the objectives of this study were to describe the tracheal structural abnormalities and correlate these changes with the respiratory function and clinical data of acromegalic patients.

Material and methods: This is a cross-sectional study that was carried out at two university hospitals. Twenty acromegalic patients underwent spirometry, forced oscillation technique, and computed tomography (CT) assessments. Dyspnea and daytime sleepiness were assessed using the Modified Medical Research Council (MMRC) scale and the Epworth Sleepiness Scale (ESS), respectively. Forty matched subjects served as controls.

Results: The acromegalic patients exhibited larger median ratios between forced expiratory flow and forced inspiratory flow at $50 \%$ of the forced vital capacity $\left(\mathrm{FEF}_{50 \%} / \mathrm{FIF}_{50 \%}\right)(2.05$ vs. $1.06, p=0.0001)$ compared with healthy volunteers. In the CT analysis, acromegalic patients exhibited larger median differences between their cervical and thoracic tracheal diameters ( $\Delta$ tracheal diameters) (3 vs. $1 \mathrm{~mm} ; p=0.003$ ). An association was found between $\mathrm{FEF}_{50 \%} / \mathrm{FIF}_{50 \%}$ and the following variables: mean resistance $(\mathrm{Rm})$, cervical tracheal diameter, and $\Delta$ tracheal diameters. $\mathrm{Rm}$ also exhibited a negative correlation with cervical tracheal diameter. Neither the MMRC scale nor the ESS exhibited any significant correlation with large airway obstruction (LAO) indices or with the measured tracheal diameters.

Conclusions: Acromegalic patients have tracheal structural abnormalities which are associated with functional indicators of LAO but not with clinical data.

Key words: acromegaly, trachea, tomography, respiratory function tests.

\section{Introduction}

Acromegaly is a chronic and systemic endocrinopathy, and the mortality rates in acromegalic patients due to respiratory complications are

\author{
Corresponding author: \\ Prof. Agnaldo José Lopes \\ State University \\ of Rio de Janeiro \\ Rua Araguaia, 1266 \\ Bloco 1/405, Freguesia, \\ Jacarepaguá \\ 22745-271 Rio de Janeiro, \\ Brazil \\ Phone: +55 212125762030 \\ E-mail: agnaldolopes.uerj@ \\ gmail.com
}


estimated to be three times higher compared with the general population [1]. In acromegalic patients, the two main respiratory complications are respiratory sleep disorders and pulmonary dysfunction [1]. Respiratory sleep disorders are associated with the onset of cardiovascular disease in the general population and are highly prevalent in acromegalic patients [2-5]. Several factors contribute to the pathophysiology of the disease, including anatomical features of the bony framework and of the soft tissues underlying the pharynx and larynx, control of ventilation, pharyngeal compliance and the degree of pharyngeal muscle tone, among others [6]. Furthermore, several abnormalities associated with pulmonary dysfunction have been described in acromegalic patients, including mechanical changes in the respiratory system elasticity, increased lung volumes, and changes in the small airways and the geometry of the respiratory muscles [7].

The functional abnormalities caused by large airway obstruction (LAO) have not been fully elucidated in acromegalic patients. The maximum flow-volume loop obtained during the spirometry procedure allows comparison between the inspiratory and expiratory flows at $50 \%$ of the forced vital capacity (FVC) to locate the obstruction [8]. Trotman-Dickenson et al. reported an increase in the ratio between the forced expiratory flow (FEF) and forced inspiratory flow (FIF) at $50 \%$ of the FVC $\left(\mathrm{FEF}_{50 \%} / \mathrm{FIF}_{50 \%}\right)$ in 17 of 34 acromegalic patients [9]. Another tool that has recently been used to evaluate LAO is the forced oscillation technique (FOT) $[10,11]$, which offers a simple and detailed approach to investigate the mechanical properties of the respiratory system [12]. This method has certain advantages over spirometry: it is effort independent, less time consuming, and requires minimal patient cooperation because it is performed during spontaneous breathing [10, 12]. However, to date, no previous studies have focused on the changes detected by the FOT in patients with acromegaly.

Although the craniofacial alterations in acromegaly have been thoroughly investigated, little is known about possible impairments of the tracheal system in these patients, either in the extrathoracic or intrathoracic segments of the trachea [13]. The trachea has been a 'forgotten zone' in the study of various disease conditions because the pathological processes involving this structure have not been given the necessary clinical recognition [14]. However, the correct diagnosis and treatment of tracheal lesions in acromegalic patients has become an area of interest and concern for many healthcare professionals because of their potential to cause significant morbidity and mortality. Therefore, in this study, we aimed to describe certain tracheal abnormalities observed on computed tomography (CT) in acromegalic patients and to correlate these changes with the clinical data and functional parameters obtained from spirometry and FOT.

\section{Material and methods}

\section{Patients}

This cross-sectional study was conducted between June 2012 and March 2013. The study involved 20 subjects with acromegaly at ages $>18$ years old who were followed up at the Clementino Fraga Filho University Hospital of the Federal University of Rio de Janeiro. Diagnoses were based on clinical features and were confirmed by high levels of growth hormone $(\mathrm{GH})$ that did not fall below $0.4 \mathrm{ng} / \mathrm{ml}$ after an oral glucose tolerance test or insulin-like growth factor I (IGF-I) levels above the upper bound of the age-specific normal range $[15,16]$. According to GH and IGF-I serum levels, patients were separated into 'active' and 'controlled' subgroups. Patients were considered to have controlled acromegaly when their IGF-I levels were within the age-adjusted reference range and when their baseline GH level was less than $1.0 \mathrm{ng} / \mathrm{ml}$ [16]; otherwise, they were considered to have active acromegaly. Patients with a history of smoking and patients with co-morbidities unrelated to acromegaly that could interfere with pulmonary function testing were excluded from the study. Untreated hypothyroidism and hypocortisolism were also considered exclusion criteria. All of the participants signed an informed consent form, and the protocol was approved by the Research Ethics Committee of the Augusto Motta University Center (UNISUAM) under number 005/2012.

\section{Anthropometry and clinical evaluation}

Body mass index (BMI) was calculated on the basis of weight and height [weight $(\mathrm{kg}) /$ height $\left(\mathrm{m}^{2}\right)$ ] using an analogue weighing scale including a stadiometer (R110, Welmy, Santa Bárbara d'Oeste, São Paulo, Brazil). The degree of dyspnea was determined using the Modified Medical Research Council (MMRC) five-point scale, which has been validated for use in Brazil [17]. Excessive daytime sleepiness (EDS) was assessed using the Epworth Sleepiness Scale (ESS), which is a self-administered questionnaire that assesses the level of sleepiness/sleep propensity in eight everyday situations, some of which are highly soporific [18]. The overall score ranges from 0 to 24 points, and a score of 10 points or more suggests EDS. The ESS has been translated into Portuguese and has been validated for use in Brazil [19]. 


\section{Pulmonary function testing}

Spirometry was conducted using a closed-circuit spirometer (Spiromax; Codex Sistemas, Ltda, Rio de Janeiro, Brazil) available at the UNISUAM following standard procedures [20]. The spirometric parameters were expressed as a percentage of the predicted values for the Brazilian population [21]. The spirometric LAO indices $\mathrm{FEF}_{50 \%} / \mathrm{FIF}_{50 \%}$ and the ratio of the forced expiratory volume in $1 \mathrm{~s}$ $\left(\mathrm{FEV}_{1}\right)$ to the peak expiratory flow (PEF) were computed [1, 22, 23].

During forced inspiration, the airway pressure in the extrathoracic portion is lower than the surrounding pressure (which is almost equal to atmospheric), and therefore this region tends to narrow. In the LAO lesions, these normal changes in airway size are greatly exaggerated. Thus, the maximum inspiratory flow is largely decreased with an extrathoracic airway obstruction, because the pressure surrounding the airways cannot oppose the negative intraluminal pressure generated with the inspiratory effort $[8,24]$. The pattern of a repeatable plateau of forced inspiratory flow suggests a variable extrathoracic airway obstruction $[8,9,13,22,24]$. In this study, a $\mathrm{FEF}_{50 \%} / \mathrm{FIF}_{50 \%}$ ratio $>1.50$ and $\mathrm{FEV}_{1} / \mathrm{PEF}$ ratio $>10$ were used as indicators of variable extrathoracic airway obstruction and variable intrathoracic airway obstruction, respectively $[9,13]$.

The instrumentation used for the FOT was developed on the Biomedical Instrumentation Laboratory of the State University of Rio de Janeiro and has been described previously [25]. To perform the FOT analysis, the volunteer remained in a sitting position while keeping his/her head in a normal position and breathing at his/her functional residual capacity through a mouthpiece. During the measurements, the subject firmly supported his/her cheeks and mouth floor using both hands, and a nose clip was worn. A minimal coherence function of 0.9 was considered adequate [25]. The mean resistance $(\mathrm{Rm})$, which is related to the airway caliber [14, 26, 27], was calculated for the frequency range from 4 to $16 \mathrm{~Hz}$. Three measurements were made, and the final result of the test was calculated as the median of these three measurements. A control group of 20 healthy volunteers at ages $>18$ years old $(14 \mathrm{fe}$ males), all non-smokers and with no history of lung disease, also performed the pulmonary function testing (spirometry and the FOT).

\section{Computed tomography}

The $\mathrm{CT}$ images were recorded in a helical $\mathrm{CT}$ scanner with 64 channels (Brilliance 40, Philips Medical Systems, Cleveland, $\mathrm{OH}$, USA). The readout time was set to four seconds with an X-ray tube current of $458 \mathrm{~mA}$ and voltage of $120 \mathrm{kVp}$ Each image acquisition consisted of a block with $2 \mathrm{~mm}$-thick cross-sections separated by $1 \mathrm{~mm}$. The images were represented by a square matrix of 768 rows and 768 columns and were recorded without gantry tilt. In all of the subjects, end-inspiratory scans were obtained. The transverse diameter of the trachea was measured in two tracheal segments. The first measurement was performed between the proximal and the middle third of the trachea (cervical trachea), and the second measurement was performed between the middle and the distal third of the trachea (thoracic trachea). The difference between both tracheal diameters ( $\Delta$ tracheal diameters) was also calculated. The CT scans were interpreted by the consensus of two chest radiologists.

For ethical reasons, the healthy controls did not undergo the $\mathrm{CT}$ scan because of the radiation emission. Thus, we performed a retrospective analysis of patients who underwent chest CT in our service. As controls, we used a group of 20 subjects at ages $>18$ years old (13 females), all non-smokers and with no history of lung disease. These subjects had undergone a CT scan due to the following reasons: staging of tumors $(n=7)$; evaluation of trauma $(n=5)$; investigation of contact with tuberculosis patients $(n=4)$; and evaluation of fever of unknown origin $(n=4)$. All of these individuals had a chest CT without any abnormalities of the airways or lungs.

\section{Statistical analysis}

To check the homogeneity of the sample, the Kolmogorov-Smirnov test was used; if a meaningful number of variables did not have a normal distribution, then non-parametric tests were selected. The results were expressed as the median and interquartile range or frequencies (percentage). Numerical variables and categorical variables were compared using the Mann-Whitney test and Fisher's exact test, respectively. Spearman's rank correlation coefficient was calculated to investigate associations. Correlation coefficients $<0.25$ (or $>-0.25$ ) represented weak correlations; coefficients between 0.25 and 0.50 (or -0.25 and -0.50 ) represented fair correlations; coefficients between 0.50 and 0.75 (or -0.50 and -0.75 ) represented moderate-to-good correlations; coefficients $>0.75$ (or $<-0.75$ ) represented good-to-excellent correlations [28]. Data analysis was performed using SAS 6.11 software (SAS Institute, Inc., Cary, NC, USA). The statistical significance level was set at $p<0.05$.

\section{Results}

Of the 40 patients with acromegaly initially recruited, 6 were excluded for the following reasons: 
refusal to participate in the study (4) and inability to reach the eligibility criteria in pulmonary function tests (2). Therefore, the acromegalic group included 13 women and 7 men with a mean age of 51.5 (44.5-60.8) years. Eleven patients had active disease, while 9 had controlled disease. Four patients had hypopituitarism, but they were on hormone replacement therapy and had normal hormone levels.

The general characteristics of acromegalic patients and healthy individuals who underwent pulmonary function tests are outlined in Table I. There were no significant differences between the acromegalic patients and healthy volunteers for any of these anthropometric characteristics. Compared with healthy volunteers, the acromegalic patients exhibited a higher median score on both the MMRC scale [1.50 (1-2) vs. $1(1-1), p=0.057]$ and ESS [10.5 (7-14) vs. 6 (2.25-10), $p=0.006]$. Moreover, 11 acromegalic patients and 3 healthy volunteers exhibited an ESS score $\geq 10 . \mathrm{A} \mathrm{FEF}_{50 \%}$ / $\mathrm{FIF}_{50 \%}$ ratio $>1.50$ was observed in 15 acromegalic patients but not in any of the control subjects, whereas a $\mathrm{FEV}_{1} / \mathrm{PEF}$ ratio > 10 was not detected in either acromegalic or control subjects. There was a statistically significant difference between the $\mathrm{FEF}_{50 \%} / \mathrm{FIF}_{50 \%}$ ratios (acromegalic patients vs healthy individuals).

Table I. General characteristics of acromegalic patients and healthy individuals who underwent pulmonary function tests

\begin{tabular}{|c|c|c|c|}
\hline Parameter & $\begin{array}{l}\text { Acromegalic patients } \\
\qquad(n=20)\end{array}$ & $\begin{array}{l}\text { Healthy individuals } \\
\qquad(n=20)\end{array}$ & $P$-value \\
\hline \multicolumn{4}{|l|}{ Demographic data: } \\
\hline Age [years] & $51.5(44.5-60.8)$ & $49(42.2-59.4)$ & 0.55 \\
\hline Female sex (\%) & $13(65)$ & $14(70)$ & 0.91 \\
\hline Weight [kg] & $77.9(65.7-81.8)$ & $73.3(62.3-78.6)$ & 0.27 \\
\hline Height $[\mathrm{cm}]$ & $165(156-169)$ & $163(155-167)$ & 0.68 \\
\hline Body mass index $\left[\mathrm{kg} / \mathrm{m}^{2}\right]$ & $29.5(26-31.5)$ & $27.4(25.1-29.6)$ & 0.42 \\
\hline \multicolumn{4}{|l|}{ Disease data: } \\
\hline Patients who had undergone surgery & $15(75)$ & - & - \\
\hline Patients who had undergone radiotherapy & $5(25)$ & - & - \\
\hline Hypopituitarism & $4(20)$ & - & - \\
\hline Arthralgia & $16(80)$ & - & - \\
\hline Arterial hypertension & $10(50)$ & - & - \\
\hline \multicolumn{4}{|l|}{ Pulmonary function parameters: } \\
\hline FVC (\% predicted) & $112(98.3-117.8)$ & $102(95.2-105.8)$ & 0.08 \\
\hline PEF (\% predicted) & $97.5(86.5-124.8)$ & 99.8 (88.0-108.9) & 0.62 \\
\hline $\mathrm{FEV}_{1}(\%$ predicted $)$ & $108(94.5-117.3)$ & $100(92.3-107.5)$ & 0.55 \\
\hline $\mathrm{FEV}_{1} / \mathrm{FVC}(\%)$ & $80.1(76.6-82.5)$ & $81.7(77.2-84.0)$ & 0.71 \\
\hline $\mathrm{FEF}_{50 \%} / \mathrm{FIF}_{50 \%}(\%)$ & $2.05(1.30-4.05)$ & $1.06(0.76-1.27)$ & 0.0001 \\
\hline $\mathrm{FEV}_{1} / \mathrm{PEF}(\%)$ & $6.76(5.92-8.20)$ & $6.20(5.67-7.79)$ & 0.27 \\
\hline $\mathrm{Rm}\left(\mathrm{cm} \mathrm{H}_{2} \mathrm{O} / \mathrm{l} / \mathrm{s}\right)$ & $2.91(2.14-4.49)$ & $2.32(1.77-3.17)$ & 0.11 \\
\hline
\end{tabular}

Values are expressed as medians (interquartile range) or number (\%). FVC - forced vital capacity, PEF-peak expiratory flow, FEV - forced expiratory volume in one second, $F E F_{50 \%} / F I F_{50 \%}$ - ratio between the forced expiratory flow and forced inspiratory flow at $50 \%$ of forced vital capacity, $F E V_{1} / P E F$ - ratio between forced expiratory volume in $1 \mathrm{~s}$ and peak expiratory flow, $R m$ - mean resistance.

Table II. Tracheal diameters of acromegalic patients and control subjects who underwent computed tomography

\begin{tabular}{|lccc|}
\hline Parameter & $\begin{array}{c}\text { Acromegaly patients } \\
(n=20)\end{array}$ & $\begin{array}{c}\text { Control subjects } \\
(n=20)\end{array}$ & $P$-value \\
\hline Cervical tracheal diameter $[\mathrm{mm}]$ & $11.8(8-14.8)$ & $14(13-18.8)$ & 0.09 \\
\hline Thoracic tracheal diameter $[\mathrm{mm}]$ & $13.6(11.3-15.8)$ & $14.5(12-16)$ & 0.91 \\
\hline$\Delta$ tracheal diameters $[\mathrm{mm}]$ & $3(2-6)$ & $1(1-2)$ & 0.003 \\
\hline
\end{tabular}

Values are expressed as medians (interquartile range). $\Delta$ tracheal diameters - difference between the diameters of the cervical and thoracic tracheal segments. 
The tracheal diameters of acromegalic patients and control subjects who underwent computed tomography are outlined in Table II. This control group had a mean age of 53.9 (46.5-62.3) years, which was similar to the acromegalic patients $(p=0.56)$. In the CT analysis (Figure 1 ), there was a statistically significant difference between the $\Delta$ tracheal diameters.

Neither the MMRC scale nor the ESS had any significant correlation with the LAO indices or with the measured tracheal diameters. An association was found between the $\mathrm{FEF}_{50 \%} / \mathrm{FIF}_{50 \%}$ ratio and the following variables: Rm, cervical tracheal diameter, and $\Delta$ tracheal diameters (Figures $2 \mathrm{~A}-\mathrm{C}$ ). The $\mathrm{Rm}$ also exhibited a negative correlation with cervical tracheal diameter (Figure 3).

\section{Discussion}

The main findings of the present study were the following: the difference between the cervical and thoracic tracheal diameters was greater in acromegalic patients compared with controls; the $\mathrm{FEF}_{50 \%} / \mathrm{FIF}_{50 \%}$ ratio was increased in acromegalic patients, which was consistent with extratho-
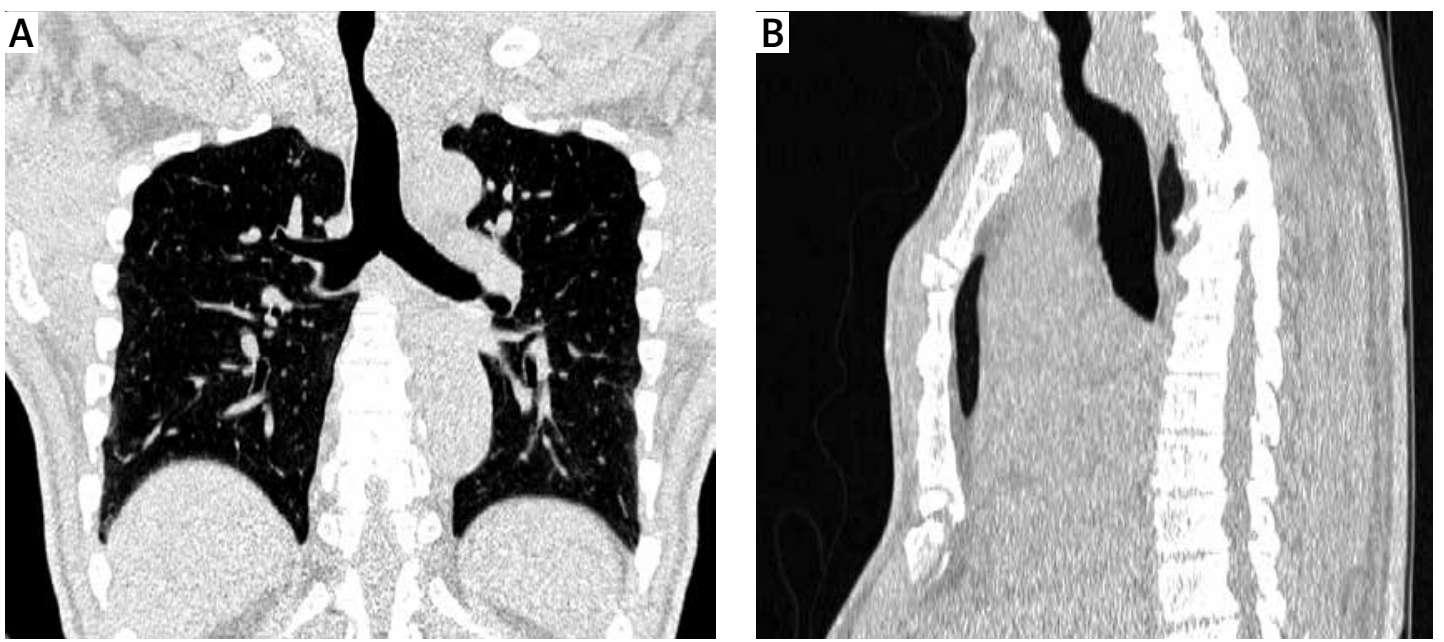

Figure 1. Trachea with irregularities and diameter variations in an acromegalic male subject. A - Inspiratory, coronal, thin-section CT scan revealed significant irregularity of the trachea. B - Inspiratory, sagittal, thin-section CT scan showed tortuosity of the trachea with variation in the diameter between the cervical and thoracic segments

A

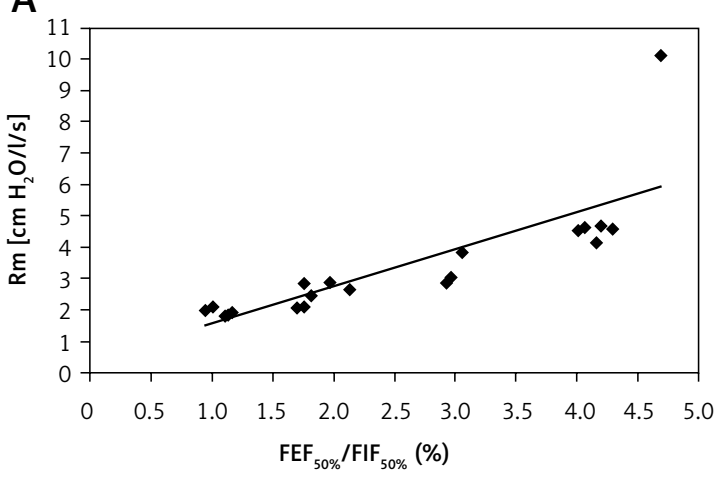

C

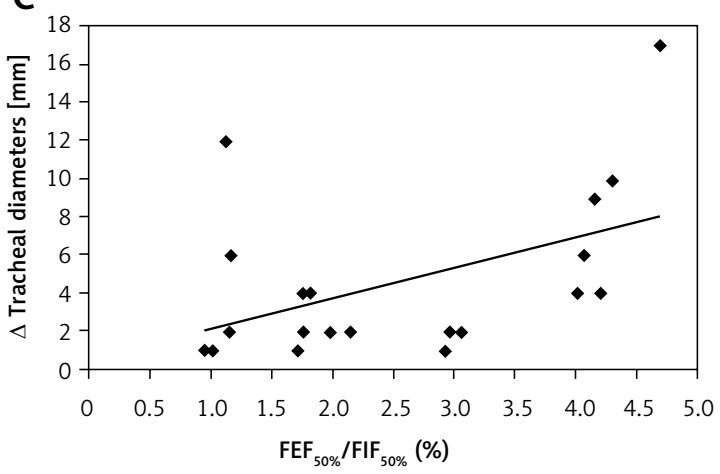

B

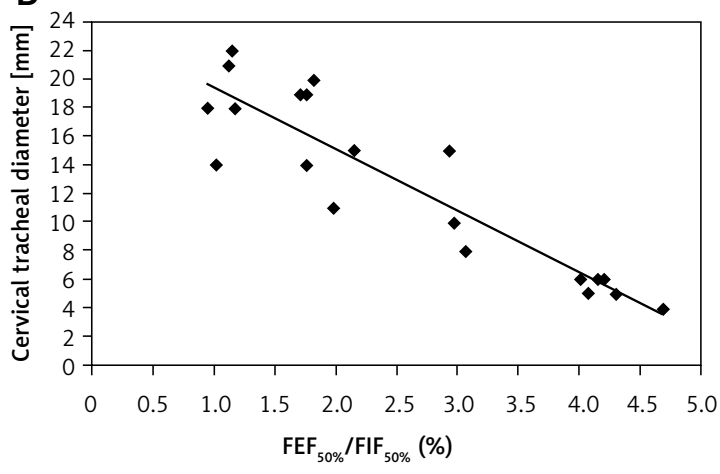

Figure 2. Relationship between the ratio of the forced expiratory flow (FEF) to the forced inspiratory flow (FIF) at $50 \%$ of the forced vital capacity $\left(\mathrm{FEF}_{50 \%} / \mathrm{FIF}_{50 \%}\right)$ and the following parameters: $A$ - mean resistance $(\mathrm{Rm})(\mathrm{rs}=0.95 ; p=0.0001)$; B - cervical tracheal diameter ( $\mathrm{rs}=-0.85 ; p=$ 0.0001 ); and $\mathbf{C}$ - difference between the diameters of the cervical and thoracic tracheal segments ( $\Delta$ tracheal diameters) $(r s=0.50 ; p=0.024)$ 
racic $L A O$; the FOT can potentially be used as an auxiliary method to detect airway obstruction in acromegalic patients because the Rm values were higher in these patients; and there were associations between the tracheal diameters and the LAO indices. To our knowledge, this is the first study to report these correlations.

Unlike the oropharynx, the trachea is not normally examined on routine examination, and in contrast to the lungs, the trachea is a potential 'blind spot' on plain chest radiography [14]. However, the trachea may be affected by a variety of systemic diseases [14, 29, 30], and these potential complications motivated us to conduct a more detailed analysis of this structure in acromegalic patients. Although the control group matched the experimental group with respect to gender and age, we observed an increase in the median tracheal diameters in acromegalic patients ( $3 \mathrm{~mm}$ vs. $1 \mathrm{~mm} ; p=0.003$ ). On neck radiography, Morewood et al. observed that the transverse tracheal diameter was statistically decreased in male but not in female subjects with acromegaly [13]. Therefore, the pathophysiological changes responsible for this tortuosity of the tracheal lumen are likely multifactorial and may involve hypertrophy of the underlying soft tissues [9]. In this respect, growth hormone $(\mathrm{GH})$ is responsible both for the increased production of collagen by connective tissues and for tissue edema due to increased reabsorption of sodium by the renal tubules [1].

Obstructive abnormalities in large-caliber airways can be detected on a maximum flow-volume loop obtained during spirometry, even in the absence of clinical suspicion. In extrathoracic LAO, obstruction occurs during inspiration because of the negative intraluminal pressure; the direction of the transmural pressure is reversed during expiration, with consequent airway opening. The opposite phenomenon occurs in intrathoracic LAO: the lumen expands during inspiration and contracts during expiration [8]. In this study, 15 of the 20 acromegalic patients had an $\mathrm{FEF}_{50 \%} / \mathrm{FIF}_{50 \%}$ ratio $>1.50$, but none of them had an $\mathrm{FEV}_{1} / \mathrm{PEF}$ ratio $>10$, suggesting that the pathophysiological mechanism responsible for LAO in these subjects was the variable extrathoracic airway obstruction. Morewood et al. used the same cut-off level for the $\mathrm{FEF}_{50 \%} / \mathrm{FIF}_{50 \%}$ to detect the variable extrathoracic airway obstruction and observed abnormalities in seven of the 26 acromegalic patients analyzed [13]. Therefore, we believe that the anatomical changes in acromegaly may compromise the intratracheal balance during inspiration and thereby promote tracheal collapsibility. Ayappa and Rapoport demonstrated that structural defects caused by fatty deposits, soft tissue infiltration, and the loss of caudal trachea traction increased upper airway collapsibility [31].

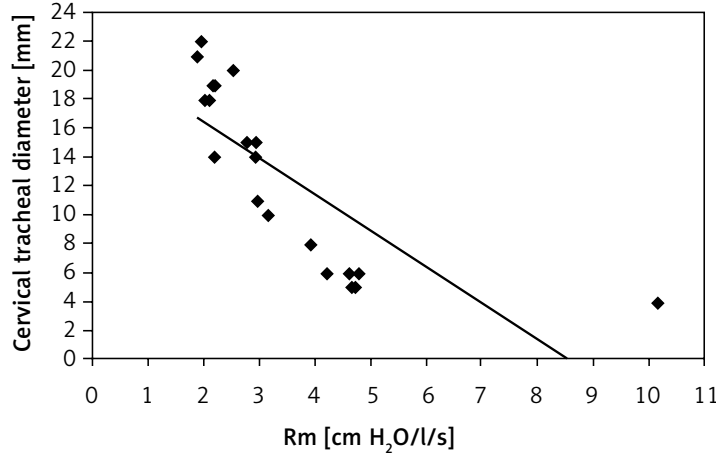

Figure 3. Relationship between the mean resistance $(\mathrm{Rm})$ and the cervical tracheal diameter (rs $=-0.93 ; p=0.0001$ )

The FOT is the method of choice for the measurement of airway resistance and can be easily modified to assess the dependence of resistance on the airflow rate [11]. Through the FOT, pressure oscillations are applied to the respiratory system by an external device, and the resulting flow fluctuations, which are related to the corresponding pressure oscillations, enable the estimation of the impedance of the respiratory system [12]. With regard to the mean resistance, this study found higher $\mathrm{Rm}$ values in acromegalic patients compared with the control group $\left(2.91 \mathrm{~cm} \mathrm{H}_{2} \mathrm{O} / \mathrm{l} / \mathrm{s}\right.$ vs. $\left.2.32 \mathrm{~cm} \mathrm{H} \mathrm{H}_{2} \mathrm{O} / \mathrm{l} / \mathrm{s}\right)$. However, these values were not statistically different between the groups, possibly because of the small sample size. Horan et al. evaluated tracheostenosis before and after tracheal dilatation procedures by rigid bronchoscopy and noted that the FOT was efficient for both identifying the obstruction and reversing the obstruction after dilatation procedures [32]. Moreover, these authors reported a strong correlation between the diameter of the tracheal stenosis and the parameters measured by the FOT. Interestingly, we also observed a good-to-excellent correlation between the Rm and the cervical tracheal diameter as well as the $\mathrm{FEF}_{50 \%} / \mathrm{FIF}_{50 \%}$ ratio, which reinforced the importance of the FOT in the study of LAO.

The most recent joint guidelines of the American Thoracic Society and the European Respiratory Society emphasize that the parameters obtained from the flow-volume loop can be indicators of potential LAO [8]. In fact, in addition to the positive correlation detected between the $\mathrm{FEF}_{50 \%}$ / $\mathrm{FIF}_{50 \%}$ ratio and $\mathrm{Rm}$, the present investigation revealed associations between $\mathrm{FEF}_{50 \%} / \mathrm{FIF}_{50 \%}$ and cervical tracheal diameter and $\Delta$ tracheal diameters. The negative correlation between the $\mathrm{FEF}_{50 \%} / \mathrm{FIF}_{50 \%}$ ratio and the cervical tracheal diameter reflected the limitation of the inspiratory flow in this tracheal region and has been previously reported in patients with LAO who underwent fibrobronchoscopy [23]. 
We also observed a difference in the MMRC scale results between the study groups, although this difference did not achieve statistical significance (1.50 in acromegalic patients vs. 1 in healthy individuals, $p=0.057$ ). However, we did not find any statistically significant correlation of this scale with the parameters studied, which was in contrast to the results reported by de Andrade and Raposo et al. [23], who found a statistically significant correlation between the MMRC scale and an obstruction in the upper third of the trachea in patients without acromegaly. For that reason, we believe that the mechanisms responsible for dyspnea in acromegalic patients are multiple and involve more than the obstruction of the trachea. As for the ESS, the score on this scale was significantly different between the study groups (10.5 in acromegalic patients vs. 6 in healthy individuals, $p=0.006$ ), which reflected the presence of EDS in the acromegalic patients studied. Sleep quality in acromegaly is known to be impaired even for patients without sleep apnea, and this impairment involves increased rates of micro-arousals and decreased duration of the rapid eye movement (REM) stage [33-35]. These changes in sleep architecture are typical of the disease and may explain the relatively high proportion of sleepy patients in our sample. Similarly to our results with the MMRC scale, we did not find any statistically significant correlation between the ESS results and the anatomo-functional parameters studied.

A critical analysis of the results is warranted. Firstly, we did not perform any bronchoscopy procedures to definitively diagnose LAO. However, even if we consider that bronchoscopy would have enabled us to understand the nature, degree, and extent of the lesions, the procedure is invasive and would not have provided information on the pathophysiological consequences. Secondly, the use of CT of the skull could provide greater support for the study of LAO in acromegaly. Lastly, a detailed sleep assessment by polysomnography could have helped us identify a possible relationship between the abnormalities detected in our study and sleep apnea, which is quite a common condition in acromegalic patients. Notwithstanding these limitations, our results indicated the involvement of the trachea in acromegaly, and this involvement was expressed in terms of both function and structure.

In conclusion, this study indicated that acromegalic patients exhibited structural changes in the trachea detected by CT. These abnormalities are associated with functional indicators of LAO but not with the clinical data obtained using the MMRC scale and ESS.

\section{Acknowledgments}

The authors wish to thank the Rio de Janeiro State Research Supporting Foundation (FAPERJ) and the Brazilian Council of Scientific and Technological Development (CNPq).

\section{Conflict of interest}

The authors declare no conflict of interest.

\section{References}

1. Colao A, Ferone D, Marzullo P, Lombardi G. Systemic complications of acromegaly: epidemiology, pathogenesis, and management. Endocr Rev 2004; 25: 102-52.

2. Kostapanos MS, Mikhailidis DP, Elisaf MS, Steiropoulos P, Papanas N. Obstructive sleep apnoea syndrome and cardiovascular risk. Arch Med Sci 2012; 8: 1115-6.

3. Peker Y, Hedner J, Norum J, Kraiczi H, Carlson J. Increased incidence of cardiovascular disease in middle-aged men with obstructive sleep apnea: a 7-year follow-up. Am J Respir Crit Care Med 2002; 166: 159-65.

4. Davì MV, Giustina A. Sleep apnea in acromegaly: a review on prevalence, pathogenetic aspects and treatment. Expert Rev Endocrinol Metab 2012; 7: 55-62.

5. Kashine S, Kishida K, Funahashi T, Shimomura I. Characteristics of sleep-disordered breathing in Japanese patients with acromegaly. Endocr J 2012; 59: 31-8.

6. Herrmann BL, Wessendorf TE, Ajaj W, Kahlke S, Teschler H, Mann K. Effects of octreotide on sleep apnoea and tongue volume (magnetic resonance imaging) in patients with acromegaly. Eur J Endocrinol 2004; 151: 309-15.

7. Camilo GB, Guimarães FS, da Silva D, et al. Pulmonary function testing and chest tomography in patients with acromegaly. Multidiscip Respir Med 2013; 8: 70.

8. Pellegrino R, Viegi G, Brusasco V, et al. Interpretative strategies for lung function tests. Eur Respir J 2005; 26: 948-68.

9. Trotman-Dickenson B, Weetman AP, Hughes JM. Upper airflow obstruction and pulmonary function in acromegaly: relationship to disease activity. Q J Med 1991; 79: 527-38.

10. Hira HS, Singh A. Significance of upper airway influence among patients of vocal cord dysfunction for its diagnosis: role of impulse oscillometry. Lung India 2009; 26: 5-8.

11. Verbanck S, de Keukeleire T, Schuermans D, Meysman M, Vincken W, Thompson B. Detecting upper airway obstruction in patients with tracheal stenosis. J Appl Physiol 2010; 109: 47-52.

12. Faria AC, da Silva KKD, Costa GM, Lopes AJ, Melo PL. Forced oscillation technique in the detection of smoking-induced respiratory changes. In: Hudak R, Penhaker M, Majernik J (eds.). Biomedical engineering: technical applications in medicine. InTech, Rijeka 2012; 291-322.

13. Morewood DJ, Belchetz PE, Evans CC, Whitehouse GH. The extrathoracic airway in acromegaly. Clin Radiol 1986; 37: 243-6.

14. Al-Qadi MO, Artenstein AW, Braman SS. The "forgotten zone": acquired disorders of the trachea in adults. Respir Med 2013; 107: 1301-13.

15. Giustina A, Barkan A, Casanueva FF, et al. Criteria for cure of acromegaly: a consensus statement. J Clin Endocrinol Metab 2000; 85: 526-9.

16. Giustina A, Chanson P, Bronstein MD, et al. Acromegaly Consensus Group: a consensus on criteria for cure of acromegaly. J Clin Endocrinol Metab 2010; 95: 3141-8. 
17. Kovelis D, Segretti NO, Probst VS, Lareau SC, Brunetto AF, Pitta F. Validation of the Modified Pulmonary Functional Status and Dyspnea Questionnaire and the Medical Research Council scale for use in Brazilian patients with chronic obstructive pulmonary disease. J Bras Pneumol 2008; 34: 1008-18.

18. Johns MW. A new method for measuring daytime sleepiness: the Epworth sleepiness scale. Sleep 1991; 14: 540-5.

19. Bertolazi AN, Fagondes SC, Hoff LS, Pedro VD, Menna Barreto SS, Johns MW. Portuguese-language version of the Epworth sleepiness scale: validation for use in Brazil. J Bras Pneumol 2009; 35: 877-83.

20. Miller MR, Hankinson J, Brusasco V, et al. ATS/ERS Task Force. Standardization of spirometry. Eur Respir J 2005; 26: 319-38.

21. Pereira CAC, Sato T, Rodrigues SC. New reference values for forced spirometry in white adults in Brazil. J Bras Pneumol 2007; 33: 397-406.

22. Modrykamien AM, Gudavalli R, McCarthy K, Liu X, Stoller JK. Detection of upper airway obstruction with spirometry results and the flow-volume loop: a comparison of quantitative and visual inspection criteria. Respir Care 2009; 54: 474-9.

23. de Andrade e Raposo LB, Bugalho A, Gomes MJ. Contribution of flow-volume curves to the detection of central airway obstruction. J Bras Pneumol 2013; 39: 447-54.

24. Kaminsky DA. Lung volumes, airway resistance, and gas distribution tests. In: Ruppel's manual of pulmonary function testing. $10^{\text {th }}$ ed. Mottram CD (ed.). Elsevier Mosby, Maryland Heights 2013; 102-34.

25. Melo PL, Werneck MM, Gianella-Neto A. New impedance spectrometer for scientific and clinical studies on the respiratory system. Rev Sci Instrum 2000; 71: 2867-72.

26. MacLeod D, Birch M. Respiratory input impedance measurement: forced oscillation methods. Med Biol Eng Comput 2001; 39: 505-16.

27. Navajas D, Farré R, Rotger M, Badia R, Puig-de-Morales M, Montserrat JM. Assessment of airflow obstruction during CPAP by means of forced oscillation in patients with sleep apnea. Am J Respir Crit Care Med 1998; 157 (5 Suppl. 1): 1526-30.

28. Dawson B, Trapp RG. Basic and clinical biostatistics. $4^{\text {th }}$ ed. Lange Medical Books/McGraw-Hill, New York 2004.

29. Zahedi-Nejad N, Bakhshayesh-Karam M, Kahkoei S, Abbasi-Dezfoully A, Masjedi MR. Normal dimensions of trachea and two main bronchi in the Iranian population. Pol J Radiol 2011; 76: 28-31.

30. Szpinda M, Daroszewski M, Szpinda A, et al. The normal growth of the tracheal wall in human foetuses. Arch Med Sci 2013; 9: 922-9.

31. Ayappa I, Rapoport DM. The upper airway in sleep: physiology of the pharynx. Sleep Med Rev 2003; 7: 9-33.

32. Horan T, Mateus S, Beraldo P, et al. Forced oscillation technique to evaluate tracheostenosis in patients with neurologic injury. Chest 2001; 120: 69-73.

33. Weiss V, Sonka K, Pretl M, et al. Prevalence of the sleep apnea syndrome in acromegaly population. J Endocrinol Invest 2000; 23: 515-9.

34. Dąbrowska AM, Tarach JS, Kurowska M, Nowakowski A. Thyroid diseases in patients with acromegaly. Arch Med Sci 2014; 10: 837-45.

35. Broncel M, Gorzelak-Pabiś P, Sahebkar A, et al. Sleep changes following statin therapy: a systematic review and meta-analysis of randomized placebo-controlled polysomnographic trials. Arch Med Sci 2015; 11: 915-26. 


\section{Appendix}

\section{Procedure of forced oscillation measurements}

\section{Introduction}

The forced oscillation technique (FOT) offers a simple and detailed approach to investigate the mechanical properties of the respiratory system [1-3]. This method characterizes the respiratory impedance and its two components, respiratory system resistance (Rrs) and reactance (Xrs). These parameters are usually measured at various frequencies using small pressure oscillations superimposed at the mouth during spontaneous breathing. The method is simple and requires only passive co-operation and no forced expiratory maneuvers. Another important advantage, particularly in pathophysiological research, is that FOT can be used to provide information on the mechanical characteristics of the respiratory system that is complementary to the information provided by spirometry.

\section{Measurement principle}

This method consists of applying small sinusoidal pressure variations to stimulate the respiratory system at frequencies higher than the normal breathing frequency and measuring the flow response. The basic instrumentation used to evaluate respiratory impedance by FOT is described in Figure 1.

An electric signal is produced in the impedance analyzer and applied to a loudspeaker that converts it to a corresponding pressure waveform. Usually, this pressure signal presents amplitude of approximately $2 \mathrm{~cm} \mathrm{H}_{2} \mathrm{O}$ (peak-to-peak). This signal is directed to the airway opening of the patient, which is connected via a mouthpiece to the set-up. The airflow ( $\left.V^{\prime}\right)$ is measured using a pneumotachograph (PNT in Figure 1), and the pressure
(P) is measured at the airway input of the patient. The resulting signals are amplified, filtered and digitized in the impedance analyzer. Then, the respiratory impedance ( $\mathrm{Zrs}$ ) is calculated using the fast Fourier transform (FFT) of these signals (1):

$$
\operatorname{Zrs}(\mathrm{f})=\frac{\mathrm{FFT}(\mathrm{P})}{\mathrm{FFT}\left(\mathrm{V}^{\prime}\right)}
$$

In practice, the sinusoidal pressure excitations are superimposed on the subject's spontaneous breathing. To enable spontaneous breathing by the patient, the system allows the individual to breathe comfortably during the experiment through a tube (bias tube in Figure 1) that operates predominantly as a pneumatic inertance element. This inertance provides a low-impedance path to the atmosphere for the low frequencies associated with the breathing process, while imposing high impedances to the high frequencies produced by the loudspeaker. To renew the air breathed by the individual, the system also in cludes a bias flow (Figure 1) of approximately $0.2 \mathrm{l} / \mathrm{s}$ near the subject's mouth.

To perform the FOT analysis, the volunteer remains seated, keeping the head in a normal position and breathing spontaneously through a mouthpiece (Figure 2). During the measurements, the subjects firmly support their cheeks and mouth floor using both hands, and a nose clip is worn.

\section{Limitations}

As for other techniques of functional assessment, the limitations of FOT and its consequences must be recognized. An important source of errors is related to the process of spontaneous breathing

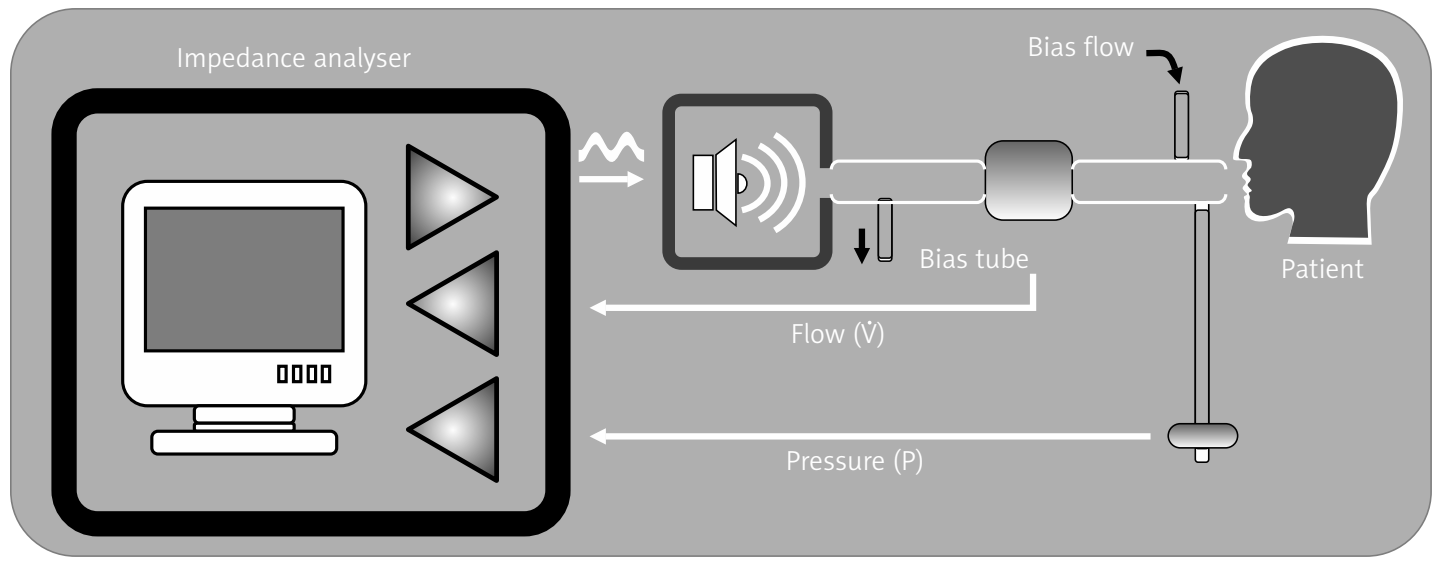

Figure 1. Basic schematic arrangement of forced oscillation respiratory impedance measurement 
of the patient, which introduces both random and systematic errors. These errors are reduced by using excitation frequencies at least 10 times higher than those present in the spontaneous ventilation process and with appropriate acceptance criteria [1-3]. The errors may be easily evaluated using the coherence function $\left(\gamma^{2}\right)$ between the pressure and airflow signals. The coherence function is the equivalent in the frequency domain of a correlation coefficient in the time domain. Perfect coherence (1.00) describes no influence of the respiratory signal in the results and may be obtained when performing the examinations in apnea conditions. In practice, the patient ventilates during the examination. The respiratory influence increases with the amplitude and frequency of the ventilation (irregular breathing or acute hyperventilation), introducing proportional reductions in the coherence function. A minimal coherence value of 0.9 is usually considered adequate [2]. Any time the coherence computed for any of the studied frequencies is smaller than this threshold, the maneuver may not be considered valid, and the examination needs to be repeated.

The compliance of the soft tissues of the upper airways, including the cheeks, comprises a mechanical impedance placed in parallel with the respiratory system. The resulting effect of this placement is to reduce the impedance measured in relation to its actual value. This effect is more pronounced in the presence of high impedances, as is the case for highly obstructive COPD patients. In practice, this drawback is minimized by asking the patient to firmly support their cheeks and mouth floor [1-3]. Artifacts can also occur if the glottis is closed or if the seal around the mouthpiece is lost during testing. Swallowing or an improper seal with the nose clip during the measurement is a reason to discard the measurement. Most of these events can easily be detected in the flow signal.

\section{Interpretation of the results}

FOT characterizes the module of the respiratory impedance (Zrs), which is associated with respiratory system resistance (Rrs) and reactance (Xrs) as described in equation (2):

$$
\mathrm{Zrs}=\sqrt{\mathrm{Rrs}^{2}+\mathrm{Xrs}^{2}}
$$

The Zrs is related to the total mechanical load provided by the respiratory system, including the resistive and reactive properties of the lung and chest wall. A convenient way to represent the behavior of the impedance tests employs the description of the resistive and reactive properties of the respiratory system, allowing a direct correlation with the mechanical properties involved.

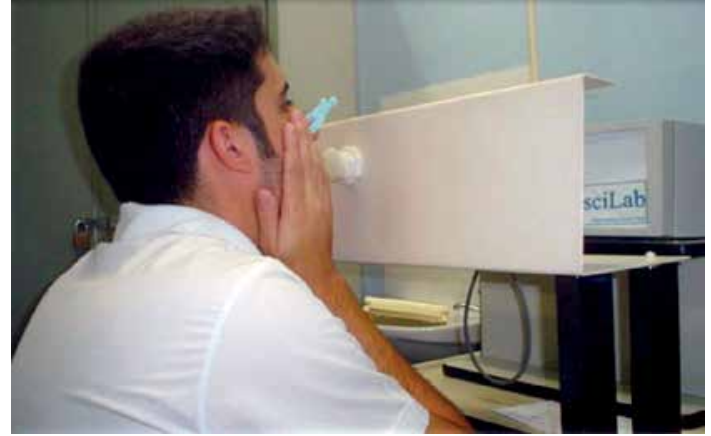

Figure 2. Example of forced oscillation respiratory impedance measurement

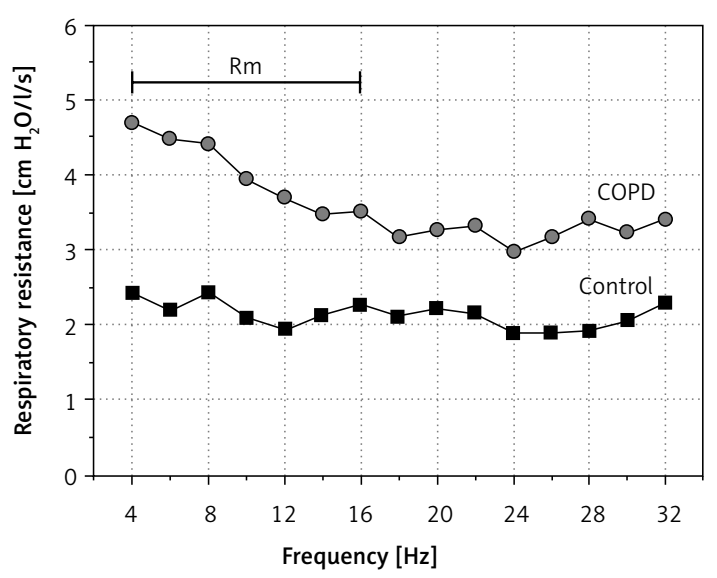

Figure 3. Examples of results for the resistance measurements obtained in normal subjects and in patients with chronic obstructive pulmonary disease (COPD)

\section{The parameter used in the present study: the mean resistance $(\mathrm{Rm})$}

The Rrs measured by FOT describes the total resistance of the respiratory system, including both frictional losses during the airflow process (similar to airway resistance measurements in plethysmography) and the resistance related to lung and chest wall tissue. We used an analysis of the mean resistance $(\mathrm{Rm})$, in the frequency range between 4 and $16 \mathrm{~Hz}$ (Figure 3). This parameter was used in the present study because it is related to airway caliber [2].

There is a consensus in the literature concerning the behavior of respiratory input impedance in normal subjects and patients [1-3]. In general, normal individuals show resistances with nearly constant values. Patients generally exhibit higher levels of resistance, decreasing with increasing frequency. Figure 3 illustrates the behavior described.

\section{References}

1. Melo PL, Werneck MM, Gianella-Neto A. New impedance spectrometer for scientific and clinical studies on the respiratory system. Rev Sci Instrum 2000; 71: 2867-72. 
2. MacLeod D, Birch M. Respiratory input impedance measurement: forced oscillation methods. Med Biol Eng Comput 2001; 39: 505-16.

3. Oostveen E, MacLeod D, Lorino H, et al. The forced oscillation technique in clinical practice: methodology, recommendations and future developments. Eur Respir J 2003; 22: 1026-41. 